\section{Compliance With Universal Precautions Among Medical Students in a Tertiary Care Center in Thailand}

TO THE EDIT OR-Occupational exposure to bloodborne pathogens poses a serious threat to healthcare workers (HCWs). Transmission of at least 20 different pathogens by injuries due to sharp instruments and devices ("sharps") and needlesticks has been reported.' HCWs in developing countries face an even higher risk because of the elevated prevalence of hepatitis $B$ virus ( $\mathrm{HBV}$ ), hepatitis $\mathrm{C}$ virus (HCV), and human immunodeficiency virus (HIV). ${ }^{2-3}$ In addition, certain medical equipment used in developing countries, such as nonretracting finger-stick lancets and glass capillary tubes used to test for common tropical diseases, enhances the risk of transmission of bloodborne pathogens. ${ }^{4}$ At Thammasart University Hospital (Pratumthani, Thailand), needlestick and sharps injuries occurred at the rate of 47 incidents per 1,000 HCWs in the year 2004. Most incidents occurred in the operating rooms, the emergency room, the medical service, the obstetrics and gynecology service, and the surgical service. Because medical students in Thailand are allowed to perform all surgical and invasive procedures, albeit under supervision because of their inexperience, they account for $47 \%$ of all such incidents reported (unpublished data, A.A.). To develop better needlestick injury prevention programs, we surveyed medical students to determine their knowledge of bloodborne pathogen transmission, their level of compliance with universal precautions, and their use of personal protective equipment.

A 50-item questionnaire was administered to 298 medical students at Thammasart University Hospital. The questionnaire was developed as part of a cooperative agreement with the Centers for Disease Control and Prevention and the National Institute for Occupational Safety and Health and had been previously validated. ${ }^{5}$ At each annual 2-hour Occupational Safety and Health Administration training session during 2004, medical students were asked to respond to multiplechoice questions. The questions were designed to identify the students' knowledge and attitudes in the following areas: (1) the risk of an unvaccinated HCW acquiring a bloodborne pathogen infection after a needlestick or sharps injury involving a patient with $\mathrm{HBV}, \mathrm{HCV}$, or HIV infection; (2) the effectiveness of postexposure prophylaxis against HIV; (3) perception of the risk of acquiring a bloodborne pathogen and attitudes about the benefits of using universal precautions; (4) patient factors that influence use of personal protective equipment and the types of personal protective equipment used.

Surveys were completed by $264(88 \%)$ of 298 medical students. The prevalences of $\mathrm{HIV}, \mathrm{HBV}$, and $\mathrm{HCV}$ infection among patients in this hospital were $21 \%, 10 \%$, and $2 \%$, respectively. Twenty-five percent of respondents correctly identified an unvaccinated HCW's risk of acquiring a bloodborne pathogen after a needlestick injury involving a patient with $\mathrm{HBV}, \mathrm{HCV}$, or HIV infection. Only $41 \%$ of respondents knew that antiretroviral therapy should be administered within a few hours after a needlestick injury involving an HIV-positive patient, and $38 \%$ believed antiretroviral therapy to be only "moderately" effective for postexposure prophylaxis. Although $73 \%$ of respondents had been fully vaccinated against HBV, only $41 \%$ correctly stated the vaccine's efficacy. Twenty-nine percent of respondents reported their lifetime occupational risk of HIV infection to be "insignificant," and $27 \%$ had not altered their practices to include new safety measures. The respondents recalled a total of 92 injuries with hollow-bore needles during the past year, although only $54 \%$ of these injuries had been reported to the employee health department. Twelve percent of respondents "only reported NSI [needlestick injury] if they knew the patient was HIV positive." During procedures, only $64 \%$ of respondents reported use of gowns, masks, and eye protection during "most"

TAвLE 1. Student Respondents' Compliance With Use of Personal Protective Equipment (PPE) During Specified Procedures $(N=169)$

\begin{tabular}{lccccc}
\hline & $\begin{array}{c}\text { No. of } \\
\text { respondents } \\
\text { who performed } \\
\text { procedure }\end{array}$ & \multicolumn{3}{c}{$\begin{array}{c}\text { PPE used during "most" or } \\
\text { "all" procedures, \% of respondents }\end{array}$} \\
\cline { 3 - 6 } Procedure $^{\mathbf{2}}$ & 169 & $166(98)$ & $47(28)$ & $40(24)$ & $27(16)$ \\
\hline Lumbar puncture & 169 & $160(95)$ & $10(6)$ & $20(12)$ & $24(14)$ \\
Phlebotomy or arterial catheter placement & 108 & $108(100)$ & $108(100)$ & NA & NA \\
Foley catheter placement & 59 & $56(95)$ & $4(7)$ & $7(12)$ & $8(14)$ \\
Intravascular catheter placement & 48 & $46(97)$ & $31(64)$ & $16(33)$ & $26(55)$ \\
Intubation & 31 & $30(98)$ & $15(48)$ & $12(39)$ & $10(32)$ \\
Central line placement & & &
\end{tabular}

NOTE. The total $N$ includes only medical students who performed a particular procedure. NA, not applicable;

${ }^{a}$ Medical students were allowed to perform these procedures under resident or ward staff's supervision. 
TABLE 2. Patient Factors That Medical Students Reported as Important in Deciding When to Use Personal Protective Equipment (PPE)

\begin{tabular}{lc}
\hline Patient factor & $\begin{array}{c}\text { No. (\%) of } \\
\text { respondents } \\
(N=169)\end{array}$ \\
\hline Positive for HIV/AIDS & $169(100)$ \\
Positive for hepatitis & $160(95)$ \\
Type of surgery or procedure & $158(94)$ \\
Known intravenous drug user & $125(74)$ \\
Trauma & $106(63)$ \\
Age & $46(27)$ \\
Sex & $35(21)$ \\
\hline
\end{tabular}

NOTE. Participants could check more than 1 answer. AIDS, acquired immunodeficiency syndrome; HIV, human immunodeficiency virus.

a Including hepatitis A and hepatitis B.

or "all" of the procedures, and few reported use of additional personal protective equipment, such as double sleeves $(8 \%$ of respondents), plastic aprons $(11 \%)$, or double gloves $(11 \%)$. Details on the number of medical students who reported use of personal protective equipment during "most" or "all" procedures are shown in Table 1. The main factors identified by medical students as being important in their decision to use personal protective equipment were knowledge of patient's HIV/AIDS status (100\% of respondents), active hepatitis (95\%), and type of surgery or procedure $(94 \%)$. Patient factors that medical students reported as important in deciding when to use personal protective equipment are summarized in Table 2.

Although use of universal precautions has been recommended for more than 2 decades, medical students in our study reported that they did not routinely comply with these precautions, and many underestimated the risk of acquiring bloodborne pathogens and were not knowledgeable about the benefit of postexposure prophylaxis after a needlestick injusry involving an HIV-positive patient. Furthermore, underreporting of needlestick injuries (only $46 \%$ were reported) was common among medical students, as has been previously reported in studies of HCWs in developed countries. ${ }^{5,6}$ Within the recognized limitations of retrospective studies, these data suggest that medical students in Thailand had inadequate knowledge and suboptimal use of universal precautions and underused important safety strategies for prevention of occupational exposure. This emphasizes the need for focused educational interventions that address the epidemiology of bloodborne pathogen transmission risk, appropriate use of personal protective equipment, procedures for reporting needlestick injuries, and current recommendations for postexposure prophylaxis against HIV.

The protection of HCWs in developing countries is largely neglected in national healthcare priorities and by the international organizations that fund healthcare initiatives. However, these countries should not delay the implementation of effective preventive strategies while awaiting additional data. Developing countries should develop national guidelines for safe work practices, postexposure prophylaxis guidelines, and HCW vaccination programs. They should also implement practical, low cost, and simple preventive strategies. Surveillance and infection control measures to prevent bloodborne pathogen transmission and cost-benefit analyses of needleless and safer sharps devices in developing countries are needed.

\section{Anucha Apisarnthanarak, MD; Hilary M. Babcock, MD; Victoria J. Fraser, MD}

From the Division of Infectious Diseases, Faculty of Medicine, Thammasart University Hospital, Pratumthani, Thailand (A.A.) and the Division of Infectious Diseases, Washington University School of Medicine, Saint Louis, Missouri (H.B., V.J.F.).

Address reprint requests to Anucha Apisarnthanarak, MD, Division of Infectious Diseases, Faculty of Medicine, Thammasart University Hospital, Pratumthani, Thailand, 12000 (anapisarn@yahoo.com).

Infect Control Hosp Epidemiol 2006; 27:1409-1410

(C) 2006 by The Society for Healthcare Epidemiology of America. All rights reserved. 0899-823X/2006/2712-0021\$15.00.

\section{REFERENCES}

1. Collins $\mathrm{CH}$, Kennedy DA. Microbiological hazards of occupational needlestick and sharp injuries. J Appl Bacteriol 1987; 62:385-402.

2. Simonsen L, Kane A, Lloyd J, Zaffran M, Kane M. Unsafe injections in the developing world and transmission of bloodborne pathogens: a review. Bull World Health Organ 1999; 77:789-800.

3. Kane A, Lloyd J, Zaffran M, Simonsen L, Kane M. Transmission of hepatitis $B$, hepatitis $C$ and human immunodeficiency viruses through unsafe infections in developing world: model-based regional estimates. Bull World Health Organ 1999; 77:801-807.

4. Sagoe-Moses C, Pearson RD, Perry J, Jagger J. Risks to health care workers in developing countries. $N$ Engl J Med 2001; 345:538-541.

5. Kim LE, Evanoff BA, Parks RL, et al. Compliance with universal precautions among emergency department personnel: implications for prevention programs. Am J Infect Control 1999; 27:453-455.

6. Tandberg D, Stewart K, Doezema D. Under-reporting of contaminated needlestick injuries in emergency health care workers. Ann Emerg Med $1991 ; 20: 66-70$

\section{Effect of a Training Program for Hospital Cleaning Staff on Prevention of Hospital- Acquired Infection}

TO THE EDITOR-Education of hospitalized patients and all healthcare providers and the control of applications following training are very important in the prevention of nosocomial infections. ${ }^{1}$ The main target populations in infection control should also include the cleaning staff, in addition to the doctors and nurses. The aim of this study was to assess 